\title{
ERRATUM
}

doi:10.1038/nature08312

\section{Kinematic variables and water transport control the formation and location of arc volcanoes}

T. L. Grove, C. B. Till, E. Lev, N. Chatterjee \& E. Médard

Nature 459, 694-697 (2009)

In this Letter, two of the Table 1 headings were incorrectly reversed. The Central Aleutians in ref. 13 and Western Aleutian in ref. 14 are comparable geographic regions. This discrepancy was not noted in the original Table 1. The corrected Table is printed below.

Table 1 | Outputs from our geodynamic models with measured arc volcano locations

\begin{tabular}{|c|c|c|c|c|}
\hline Arc name & Convergence rate (km per million years) & Slab dip (degrees) & Arc-trench distance $(\mathrm{km})$ & Depth to slab (km) \\
\hline Central Aleutians & 60 & 58 & 176 (ref. 14); 44 (ref. 13) & 99 (ref. 14); 90 (ref. 13) \\
\hline Model similar to the central Aleutians & 60 & 64 & 40 & 80 \\
\hline New Zealand & 36 & 50 & 96 (ref. 14); 92 (ref. 13) & 123 (ref. 14); 110 (ref. 13) \\
\hline Model similar to New Zealand & 40 & 40 & 104 & 70 \\
\hline
\end{tabular}

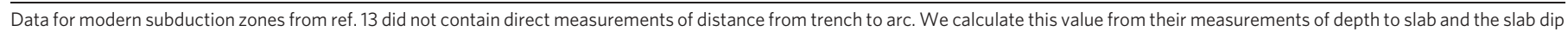
by a simple geometric approximation: (depth to slab)/tan (slab dip). 